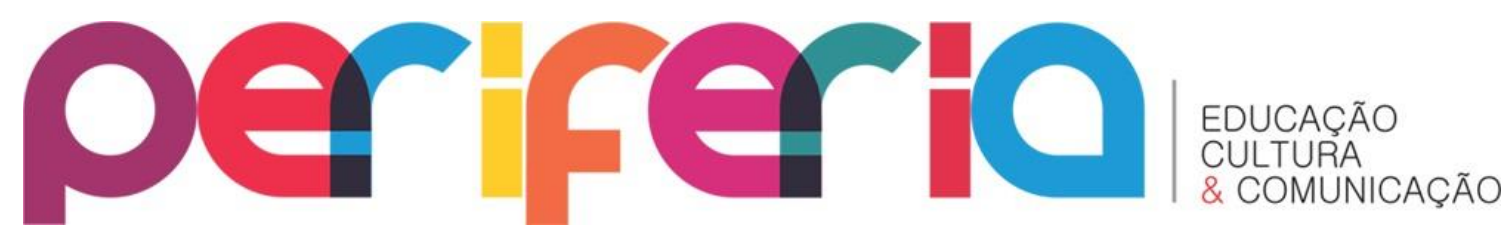

\title{
PANORAMA DA SITUAÇÃO SOCIOECONOMICA DE ALUNOS DO ENSINO FUNDAMENTAL DE ESCOLAS DE SÃO JOÃO DE MERITI-RJ
}

\author{
Tania de Assis Souza Granja ${ }^{1}$ \\ Maria de Lourdes Rangel Tura ${ }^{2}$ \\ Universidade do Estado do Rio de Janeiro
}

\section{RESUMO}

Este artigo é desdobramento da pesquisa de doutorado realizada em duas escolas municipais da rede pública de São João de Meriti. Apresenta-se uma reflexão sobre o perfil socioeconômico de alunos e alunas do 70 ano de escolaridade que participaram do estudo. Trata-se de uma pesquisa de cunho etnográfico em que, na primeira parte do trabalho, foram feitos questionários com alunos e alunas, visando seu ambiente, condições de vida e renda familiar. O aporte teórico constituiu-se de Bourdieu (1999), Tura (2011), Freitas (2007) e Montali; Tavares (2008), dentre outros. Os dados coletados ajudam a conhecer um pouco da realidade social e econômica de alunos e alunas que frequentam na atualidade o ensino público daquele município, com seus impactos sobre o cotidiano da escola.

Palavras-chave: Ensino fundamental, cotidiano escolar, situação socioeconômica de alunos/as, abordagem etnográfica.

\section{PANORAMA OF THE SOCIOECONOMIC SITUATION OF PUPILS IN THE FUNDAMENTAL LEVEL OF EDUCATION IN MUNICIPAL SCHOOLS OF SAO JOAO DE MERITI-RJ CITY ABSTRACT}

This article results from the doctorate research, made in two municipal schools of the S. João de Meriti city. A reflection is made about the socioeconomic profile of the pupils, which are in the $7^{\text {th }}$ year of education, who took part in this study. This research has an ethnographic approach, where, in the first part of the work, mixed survey questionnaires were made with both male and female pupils, focusing on their environment, life conditions and familiar income. The theoretical basis consisted of Bourdieu (1999), Tura (2011), Freitas (2007), Montali; Tavares (2008) amongst others. The data collected help us to know a little bit more about the social and economic reality of the pupils, who currently go to public schools and its impacts on the daily school life.

Keywords: primary education, daily school life, socioeconomic profile of the pupils, ethnographic approach.

\footnotetext{
${ }^{1}$ Doutora em Educação, professora substituta da Universidade do Estado do Rio de Janeiro, membro do grupo de pesquisa Currículo: sujeitos, conhecimento e cultura, do Programa de Pós-Graduação em Educação (ProPEd/UERJ). E-mail: tasgranja@gmail.com.

2 Professora do Programa de Pós-Graduação em Educação (ProPEd/UERJ), orientadora da tese Construção do currículo escolar: a produção de sentidos de professores e alunos sobre as práticas pedagógicas no cotidiano da escola da Baixada Fluminense. E-mail: Itura@centroin.com.br.
} 


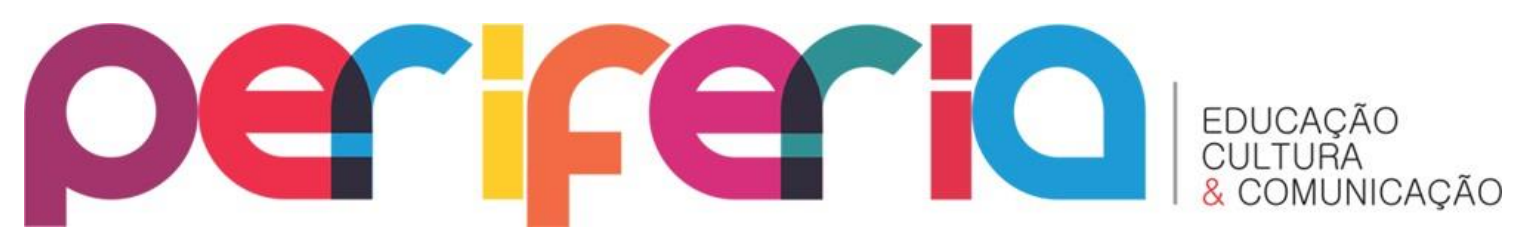

\section{INTRODUÇÃO}

Neste texto apresentamos um breve panorama da situação socioeconômica de alunos e alunas que participaram de uma pesquisa realizada em duas escolas que compõem a rede pública do município de São João de Meriti, na Baixada Fluminense. Esses estudantes na época cursavam o 70 ano de escolaridade do ensino fundamental e suas famílias eram participantes do Programa Bolsa Família ${ }^{3}$. Chamavam a nossa atenção as condições habitacionais em que viviam; a maioria morava no entorno das escolas. Decidimos, então, conhecer um pouco da realidade social e econômica dos alunos e alunas que frequentavam as instituições educacionais pesquisadas.

Nesta pesquisa de cunho etnográfico foram adotados procedimentos como observação participante, análise documental, entrevista, questionário, gravação em áudio, fotografias e uma oficina de produção de textos em ambas as escolas. Nessa abordagem realizamos uma série de novos direcionamentos e novas focalizações durante o trabalho de campo que permitiram acertos de rota (TURA, 2011). Para a construção deste texto, fizemos um recorte no material coletado e utilizamos os dados do questionário misto aplicado a alunos e alunas num momento inicial do estudo. Tínhamos como foco traçar um perfil socioeconômico de alunos e alunas e suas famílias, visando conhecer seu ambiente, condições de vida e renda familiar. Neste

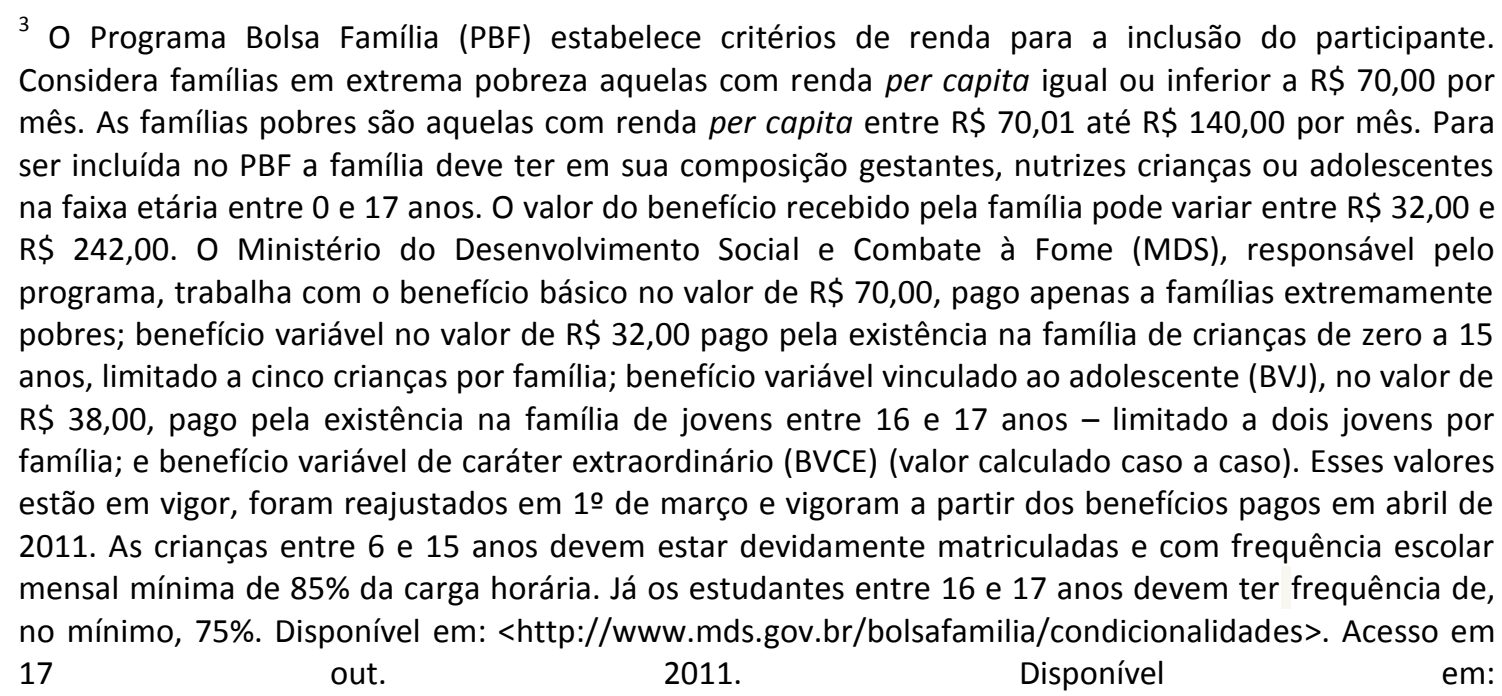
<http://www.caixa.gov.br/voce/social/transferencia/bolsa_familia/index.asp>. Acesso em 17 out. 2011. 


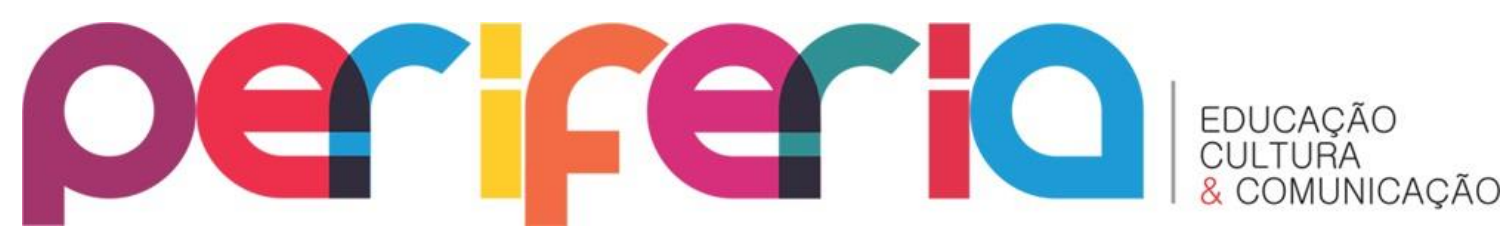

estudo, o Programa Bolsa Família é tomado como referência pelos parâmetros de renda que são definidos nele, de modo que seus participantes estão categorizados na linha da pobreza e extrema pobreza.

\section{AS ESCOLAS PESQUISADAS: UMA BREVE CONTEXTUALIZAÇÃO}

Na definição do lócus da pesquisa implicava escolher instituições de ensino com contorno diferenciado, uma vez que eram necessárias algumas condições peculiares ao estudo. Elas precisavam reunir três aspectos: a escola ser organizada na modalidade de ciclo no segundo segmento do Ensino Fundamental (do 6으 ao 9을 ano de escolaridade), ter um número significativo de alunos com defasagem idade-série com dois ou mais anos de atraso escolar e conter indicadores de avaliação no IDEB (Índice de Desenvolvimento da Educação Básica) abaixo e acima da média nacional, respectivamente nas escolas pesquisadas, visto que nos interessava discutir questões ligadas às novas políticas curriculares e ao desempenho escolar.

A primeira escola pesquisada durante o ano letivo de 2010 é um centro integrado de educação pública (CIEP) situado no alto de um morro, cujo entorno é uma favela onde se encontra muita pobreza, evidenciada nas casas de alvenaria crua sem nenhuma proteção de revestimento externo, expostas à umidade e de construção precária.

O CIEP, que era administrado pelo estado, foi municipalizado em 1999. A estrutura de ensino se dá na modalidade de ciclos de formação, distribuídos da seguinte

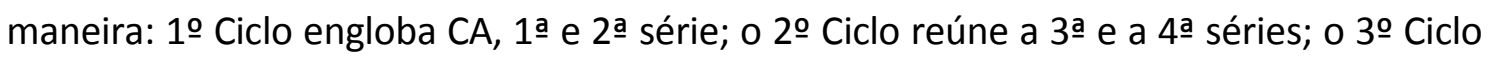

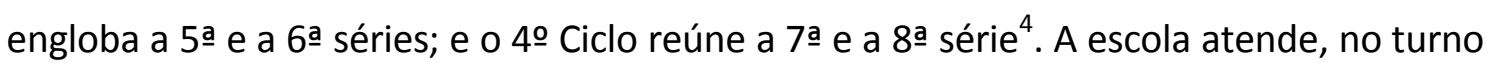
da manhã, o 1ㅇ e o 2을 Ciclos; no turno da tarde, o 3으 e o 4‥ Em ambos os turnos havia

\footnotetext{
${ }^{4}$ A Resolução $n^{0}$ 04/10 - SEME, de 20 de abril de 2010, dispõe sobre a organização do ensino fundamental da Rede Municipal de São João de Meriti, extinguindo a organização na modalidade de ciclo, que vigorou no período 1999-2010, definindo, assim, para os anos iniciais, o ciclo de alfabetização com duração de três anos, seguido do 40 e 50 ano de escolaridade. $O$ segmento denominado anos finais ficou constituído pelos 6 7ㅇ 8 e 9ㅇao an de escolaridade. Tal resolução determinava a organização das escolas da rede em anos de escolaridade. Contudo, a nova nomenclatura foi utilizada tão somente para a organização das turmas, ficando o trabalho pedagógico (práticas, currículo e avaliação) inalterados, funcionando sob a égide da Proposta de Ação Político-Pedagógica SEMEar, durante toda a nossa pesquisa de campo.
} 


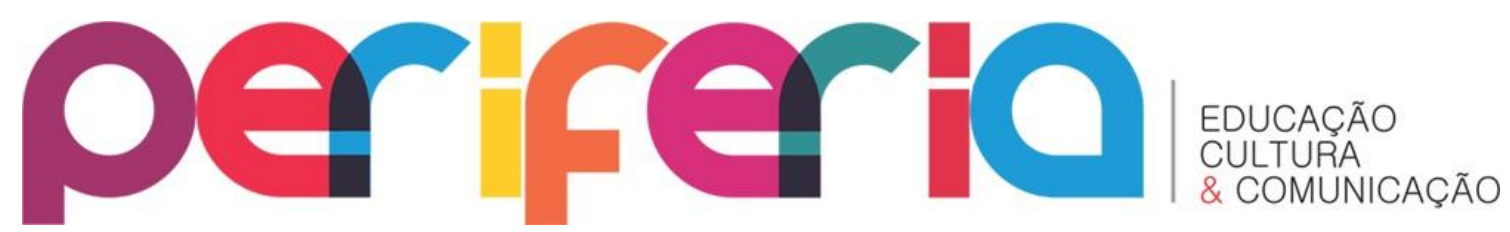

classe de alunos com necessidades educacionais especiais. No turno da noite, atende a alunos da Educação de Jovens e Adultos - EJA (4ㅇa ao 8ㅇ ano de escolaridade). Pela manhã, estavam matriculados 319 alunos; à tarde totalizavam 276 alunos; e à noite havia 99 alunos, perfazendo 694 alunos. Para este estudo, foram acompanhadas duas turmas do 70 ano de escolaridade, a 71A e a 71B, equivalentes à 6a série; cada turma tinha 36 alunos. Como as duas turmas funcionavam no horário da tarde, os mesmos professores se revezavam nas disciplinas, reduzindo, assim, o quantitativo de profissionais. A escola tinha o programa federal Mais Educação e atendia alguns alunos no contraturno, oferecendo atividades em forma de oficinas de recreação, capoeira, informática, hip hop, judô e letramento. Neste trabalho, essa escola será denominada CP.

A escolha da segunda escola pesquisada obedeceu aos mesmos critérios descritos, consubstanciados em três aspectos: ser organizada em ciclos, ter aluno com defasagem idade-série e ter avaliação no IDEB cujo indicador foi acima da média no

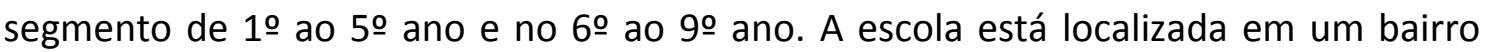
pobre do município e é cercada por favela, ou melhor, localiza-se na parte baixa da favela, beirando a rua. Neste trabalho, essa escola será denominada EM.

A escola foi fundada em 1971, funcionando com ensino primário (atual ensino fundamental de 1음 5o ano de escolaridade). Em 1998, foi ampliado o atendimento à população, passando a atender do 10 ao 9o ano de escolaridade. A partir de 2011, por decisão da SEME, estava atendendo somente ao segundo segmento do ensino fundamental, ou seja, do 6으 ao 9 ano de escolaridade. A escola funciona com três turnos da seguinte maneira:

- Manhã: Ensino fundamental no primeiro turno (das $7 \mathrm{~h}$ às $12 \mathrm{~h} 15 \mathrm{~min}$ ) atende 7ano (71A, 71B, 71C): 3 turmas; 8ano (81A, 81B, 81C): 3 turmas; 9ano (91A, 91B, 91C): 3 turmas;

- Tarde: Ensino fundamental no segundo turno (das $12 \mathrm{~h} 45 \mathrm{~min}$ às $18 \mathrm{~h}$ ) atende 60ano (61A, 61B, 61C, 61D, 61E): 5 turmas; 7ano (71D, 71E, 71F): 3 turmas; EJA - Ed. Especial: 1 turma, com 14 alunos apresentando diferentes necessidades especiais.

- Noite: EJA - Alfabetização. 


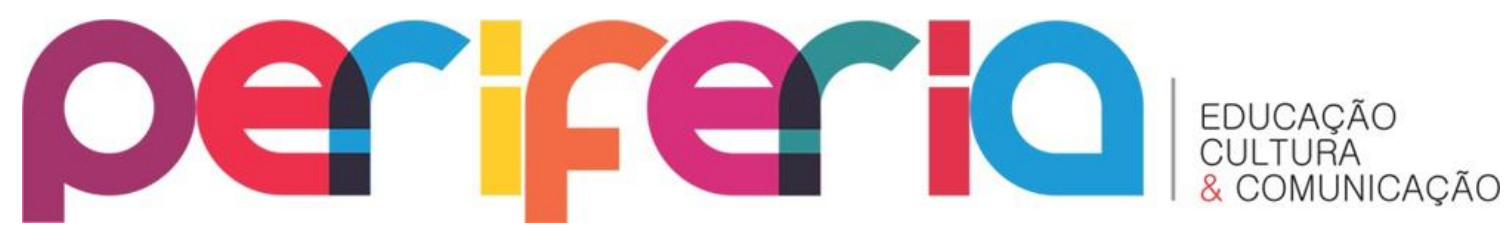

Apresentamos a seguir um quadro síntese, em que pode ser visualizado, no conjunto, o atendimento aos 898 alunos realizado pela instituição.

Quadro 1. Organização da Escola EM

\begin{tabular}{|c|c|}
\hline \multicolumn{2}{|c|}{ Diurno } \\
\hline EJA Diurno (Ed. Especial) & 14 alunos \\
\hline 60 Ano de Escolaridade & 192 Alunos \\
\hline 70 Ano de Escolaridade & 206 Alunos \\
\hline 80 Ano de Escolaridade & 132 Alunos \\
\hline 9o Ano de Escolaridade & 83 Alunos \\
\hline Total & 627 \\
\hline & \\
\hline Alfa & 25 Alunos \\
\hline 4a Etapa & 14 Alunos \\
\hline 5a Etapa & 53 Alunos \\
\hline 6a Etapa & 41 Alunos \\
\hline 7a Etapa & 71 Alunos \\
\hline 8a Etapa & 47 Alunos \\
\hline 9a Etapa & 264 Alunos \\
\hline Total & 271 \\
\hline Total da EJA & 898 Alunos \\
\hline Total de Alunos &
\end{tabular}

Desde 2010 , os alunos desta escola também eram atendidos pelo programa federal Mais Educação no contraturno, oferecendo atividades em forma de oficinas. $O$ programa teve início em agosto e as oficinas selecionadas foram: Letramento (2a e 4a feira); Matemática (3a e 5a feira); jornal escolar (3a e 5ํ feira); caratê (2a e 4a feira); Judô (6a feira); laboratório de ciências (5a feira).

Os alunos que participavam do programa Mais Educação foram selecionados obedecendo aos critérios de déficit de aprendizagem e assiduidade. Contudo, a participação não era obrigatória. O programa atendia 118 alunos frequentes durante o 1ㅇ e 2 - turnos. Os alunos recebiam lanche e almoço, garantindo a permanência na escola com carga horária maior. As monitorias do programa Mais Educação eram pagas com verba recebida pela escola ao custo de $\mathrm{R} \$ 300,00$ mensais por oficina. $O$ pagamento dos "oficineiros" (como eram chamados) na instituição seguia um critério diferenciado da primeira escola. Cada monitor podia ministrar somente uma oficina e não havia vínculo empregatício com a escola. O planejamento seguia a orientação do 


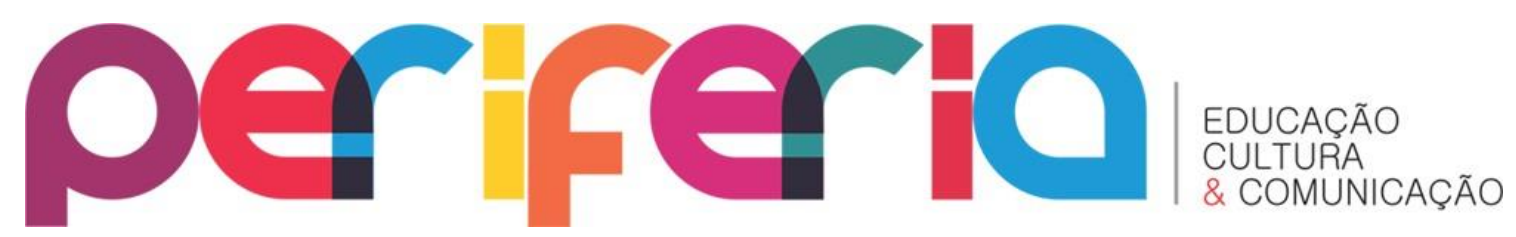

professor coordenador designado pela diretora. Os monitores contavam com os materiais básicos, seguindo os padrões de especificação do Governo Federal, podendo trabalhar livremente, pondo em prática um planejamento prévio no intuito de reduzir as dificuldades de aprendizagem de cada ano de escolaridade.

A EM possui infraestrutura composta de nove salas de aula, uma sala para o programa Mais Educação, secretaria, sala da direção, sala de orientação pedagógica e educacional, sala de leitura/biblioteca, duas salas com laboratório de informática (Proinfo e Telecentro), cozinha, refeitório, despensa, banheiro de funcionários, banheiro de alunos. Nessa escola o trabalho de campo teve início no começo de julho de 2011, no período anterior ao recesso escolar, e foi encerrado em dezembro do mesmo ano.

\section{A PESQUISA DE CAMPO: ALGUMAS PISTAS PARA PENSAR A REALIDADE SOCIAL DE}

\section{ALUNOS E ALUNAS}

Elaboramos um questionário misto que foi respondido pelos pais e/ou responsáveis de alunos e alunas do estudo. O objetivo era obter caracterização socioeconômica e fazer levantamento de dados, de modo a traçar o perfil dos alunos e suas famílias. O questionário foi levado para casa pelo aluno para preenchimento; foi combinado que ele retornaria com o instrumento na semana seguinte, quando da visita do pesquisador. Assim, após o recolhimento do questionário, o procedimento foi retomado ao término das entrevistas para a confirmação dos dados e/ou retificação. 0 preenchimento foi feito em conjunto pela pesquisadora.

$\mathrm{O}$ instrumento foi dividido em quatro partes. A primeira parte tem a identificação; a segunda parte reunia informações que possibilitassem realizar um panorama da situação familiar, constando o total de componentes familiares, grau de parentesco dos que residiam na casa e renda familiar; a terceira parte informava os bens duráveis possuídos pela família e, por fim, a quarta parte informava o nível de escolaridade do responsável e alguns dados sobre o Programa Bolsa Família (PBF). Foram 30 participantes no levantamento, sendo 14 do CP (dois alunos não trouxeram 


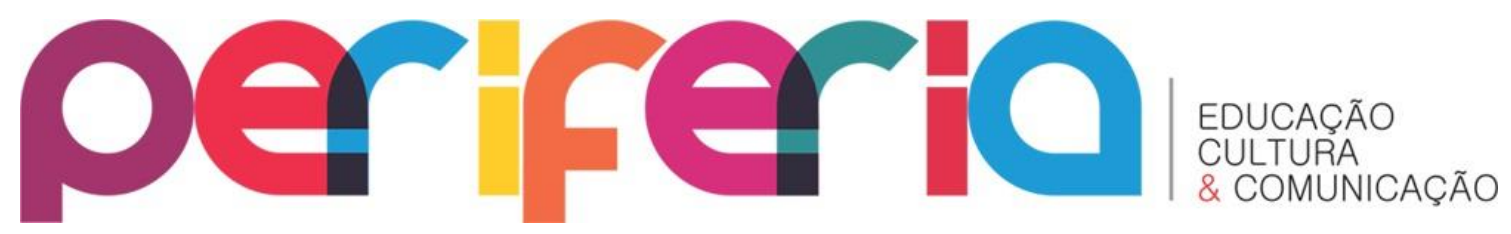

o questionário) e 16 da EM. Todo o material foi organizado, os dados foram tabulados e divididos em temas procurando identificar e caracterizar o perfil socioeconômico das famílias. A análise forneceu alguns indicadores.

Num primeiro olhar, o Quadro 2 revela dados sobre a renda familiar de alunos e alunas e o quantitativo de pessoas por domicílio (PD), por escola (o CP com 14 participantes 5 e a EM com 16 participantes).

Quadro 2 - Renda Familiar (em salários mínimos - SM) e Pessoas por domicílio (PD)

\begin{tabular}{|c|c|c|c|c|c|c|c|c|c|c|c|c|c|c|c|c|c|c|}
\hline \multicolumn{19}{|c|}{ Renda familiar (em salários mínimos - SM) e Pessoas por domicílio (PD) } \\
\hline \multirow{2}{*}{ ESCOLAS } & \multicolumn{3}{|c|}{ Até 1 SM } & \multicolumn{3}{|c|}{ De 1 a 2 SM } & \multicolumn{3}{|c|}{ De 2 a 3 SM } & \multicolumn{3}{|c|}{ De 3 a 4 SM } & \multicolumn{3}{|c|}{ De 4 a 5 SM } & \multicolumn{3}{|c|}{+ de 5 SM } \\
\hline & $\mathrm{n}$ & $\%$ & PD & $\mathrm{n}$ & $\%$ & PD & $\mathrm{n}$ & $\%$ & PD & $\mathrm{n}$ & $\%$ & PD & $\mathrm{n}$ & $\%$ & PD & $\mathrm{n}$ & $\%$ & PD \\
\hline $\mathrm{CP}$ & 8 & $57 \%$ & 3 a 6 & 5 & $36 \%$ & 4 a 9 & 1 & $7 \%$ & 5 & - & - & - & - & - & - & - & - & - \\
\hline EM & 13 & $81 \%$ & 3 a 6 & 1 & $6 \%$ & 6 & - & - & - & - & - & - & 2 & $13 \%$ & 4 & - & - & - \\
\hline
\end{tabular}

Fonte: Dados da pesquisa de campo 2010 e 2011. Elaboração: Tania Granja.

É notória a prevalência das famílias na faixa de renda familiar de até 1 salário mínimo. Os casos em que a renda familiar varia de 1 a 2 salários mínimos ocorrem porque duas ou mais pessoas naquela família trabalhavam na informalidade e, no somatório da renda familiar, atingiam patamar mais elevado. Em geral, o mesmo ocorre nas demais faixas.

Ao examinar o gráfico a seguir, visualizamos a distribuição da renda do grupo pesquisado, tendo em conta a totalidade dos participantes.

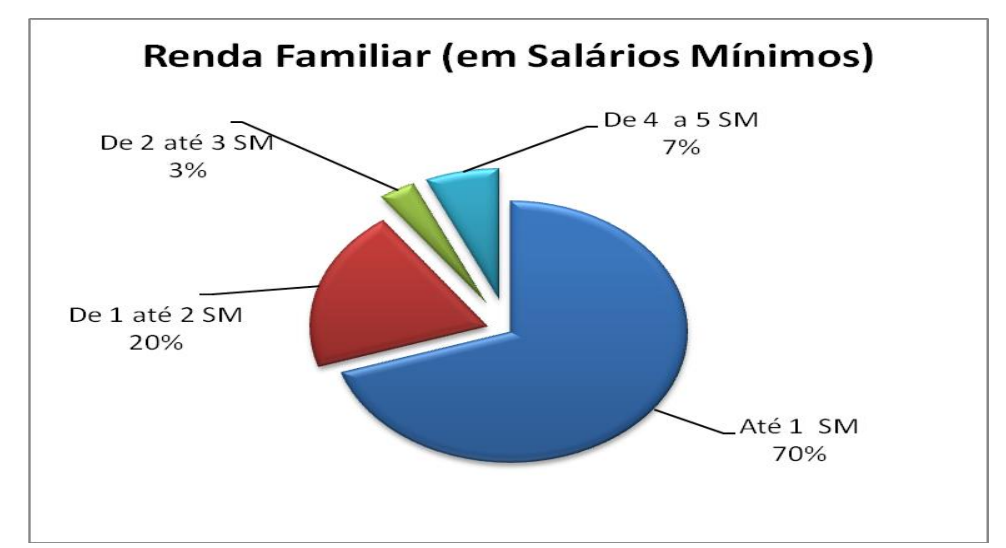

Gráfico 1. Renda familiar em salários mínimos (SM)

Fonte: Dados da pesquisa de campo 2010 e 2011. Elaboração: Tania Granja.

\footnotetext{
${ }^{5}$ No CP ocorreu que dois alunos não trouxeram o questionário para o levantamento. Desse modo, para a coleta de dados do levantamento socioeconômico participaram 30 do total de 32 participantes do estudo.
} 


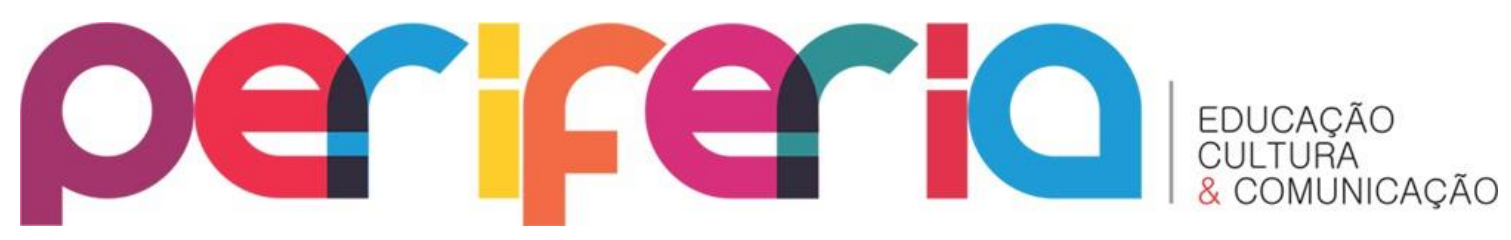

É possível visualizar a predominância nas faixas salariais mais baixas. Há uma variação de renda familiar na margem de até 1 salário mínimo, que vai de $R \$ 230,00$ a $\mathrm{R} \$ 510,00$. Na faixa de renda de 1 a 2 salários mínimos, a renda familiar variou de $\mathrm{R} \$$ 600,00 a $\mathrm{R} \$ 1.000,00$. Neste estudo, os dados coletados no campo indicam que as menores faixas de rendas das famílias estão localizadas no grupo também de menor escolaridade, o que será mostrado no Quadro 3, mais adiante. Alguns estudos ${ }^{6}$ mostram a correspondência entre nível de renda e escolarização. Apontam, também, para uma relação entre a renda maior ou menor e a própria inserção no mercado, segundo o grau de escolaridade.

Na terceira parte do levantamento, foi reunido um elenco de bens duráveis que constituem dados complementares à renda familiar. $\mathrm{O}$ quadro a seguir traz alguns indicadores.

Quadro 3. Bens duráveis por família de cada escola

\begin{tabular}{|c|c|c|c|c|}
\hline \multirow{2}{*}{ BENS DURÁVEIS } & \multicolumn{2}{|c|}{ CP } & \multicolumn{2}{c|}{ EM } \\
\cline { 2 - 5 } & $\mathbf{N}$ & $\%$ & N & $\%$ \\
\hline Casa própria & $12^{(*)}$ & $86 \%$ & 9 & $56 \%$ \\
\hline Casa alugada & 1 & $7 \%$ & 3 & $19 \%$ \\
\hline $\begin{array}{c}\text { Casa } \\
\text { emprestada/cedida }\end{array}$ & $3^{\left({ }^{*}\right)}$ & $21 \%$ & 4 & $25 \%$ \\
\hline Televisão & 14 & $100 \%$ & 16 & $100 \%$ \\
\hline Geladeira & 14 & $100 \%$ & 16 & $100 \%$ \\
\hline Micro-ondas & 2 & $14 \%$ & 4 & $25 \%$ \\
\hline Computador & 4 & $28 \%$ & 5 & $31 \%$ \\
\hline Aparelho DVD & 10 & $71 \%$ & 13 & $81 \%$ \\
\hline Lava-roupa & $3^{\left({ }^{*}\right)}$ & $21 \%$ & 9 & $56 \%$ \\
\hline Aparelho de som & 10 & $71 \%$ & 13 & $81 \%$ \\
\hline
\end{tabular}

\footnotetext{
${ }^{6}$ Ver Relatório do Tribunal de Contas do Estado do Rio de Janeiro (TCERJ) e Secretaria Geral de Planejamento de Caxias, 2004 e 2006, que mostra, nos respectivos estudos, que, à medida que aumenta a escolaridade, a renda média sobe expressivamente em todos os anos analisados no período (19922004). Desse modo, fica evidente a correspondência significativa entre os níveis de educação e a remuneração que os indivíduos podem alcançar em função da sua escolaridade; Montali; Tavares (2008, p. 215), no seu estudo, identificam nos arranjos familiares das regiões metropolitanas grupos cuja menor escolaridade é um agravante para as condições de sobrevivência desses domićlios, considerando-se a crise do emprego a partir da década de 1990 e a exigência de melhor qualificação profissional na disputa por um posto de trabalho.
} 


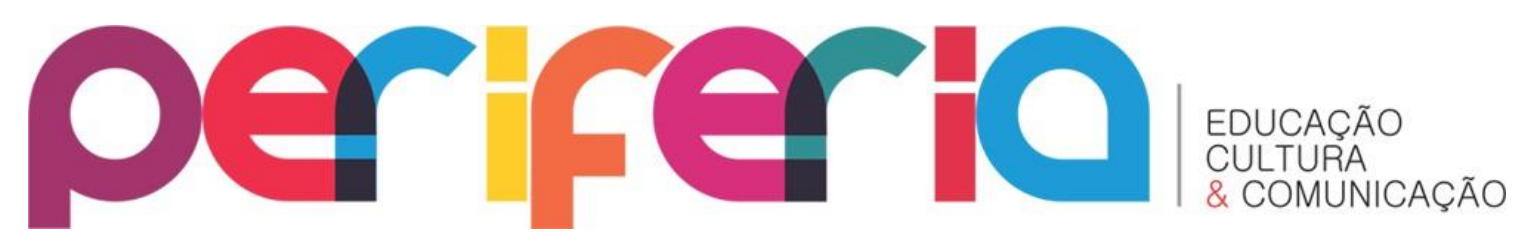

\begin{tabular}{|c|c|c|c|c|}
\hline Lava-louça & - & - & - & - \\
\hline Notebook & - & - & 1 & $6 \%$ \\
\hline TV a cabo & - & - & 4 & $25 \%$ \\
\hline Internet & $2^{(*)}$ & $14 \%$ & 4 & $25 \%$ \\
\hline Freezer & $3^{\left({ }^{*}\right)}$ & $21 \%^{\left({ }^{*}\right)}$ & 5 & $31 \%$ \\
\hline Telefone fixo & 10 & $71 \%$ & 4 & $25 \%$ \\
\hline Telefone celular & 8 & $57 \%$ & 16 & $100 \%$ \\
\hline Carro & $1^{(*)}$ & $7 \%$ & 2 & $13 \%$ \\
\hline Motocicleta & - & - & - & - \\
\hline
\end{tabular}

Fonte: Dados da pesquisa de campo 2010 e 2011.

Elaboração: Tania Granja.

Cabem, aqui, alguns esclarecimentos em relação aos itens que se apresentam com asterisco $(*)$, na medida em que comportam algumas particularidades expressas pelos participantes da pesquisa. No item casa própria, durante o levantamento dos dados, foi esclarecido com os participantes se a casa era deles e se havia documentação de propriedade. Então explicaram que as pessoas moram no quintal da avó, da mãe ou da sogra e lá construíram suas casas; alguns pagavam IPTU e outros não pagam, porque não há regularização da propriedade (RGI). Nenhum dos participantes tinha escritura definitiva da casa em que morava.

No levantamento, o item casa emprestada/cedida designa a situação em que moravam no quintal de algum parente, numa moradia que já existia, e não pagavam nada de aluguel porque, segundo eles, "moram de favor" (sic) ou parente que emprestou por um período combinado. No item lava-roupa, alguns consideraram o tanquinho elétrico como máquina de lavar roupa, uma vez que o aparelho dá certa comodidade na execução da tarefa, deixando de ser totalmente manual. No item internet, informaram que se trata de "gatonet" (sic). No item freezer, alguns participantes tinham nas suas próprias moradias uma espécie de comércio (bar, birosca), e o eletrodoméstico era utilizado para armazenamento das mercadorias que vendiam e, eventualmente, para alimentos da própria família. No item carro, um dos participantes considerou sua Kombi que era usada para transporte e venda de frutas e legumes na comunidade. Os demais assinalaram o item como carro de passeio. A distribuição dos bens está no gráfico a seguir. 


\section{periferio}

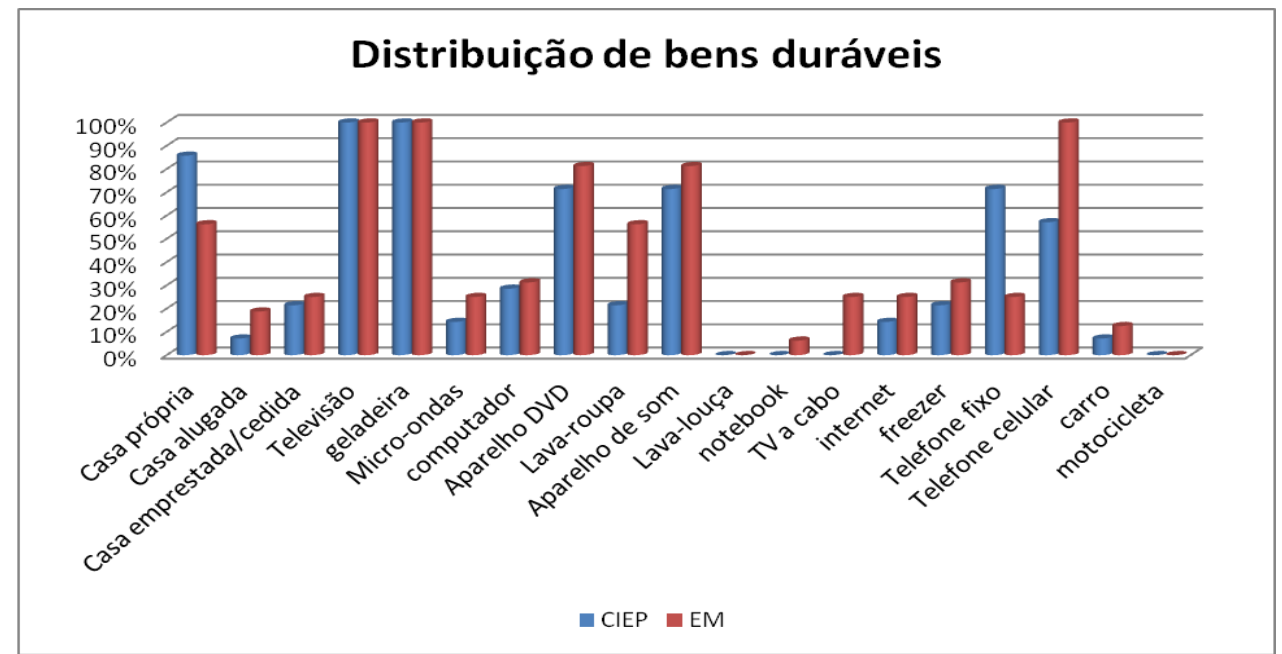

Gráfico 2. Distribuição de bens duráveis por família.

Fonte: Dados da pesquisa de campo 2010 e 2011. Elaboração: Tânia Granja.

No que tange à aquisição de bens duráveis, há predominância de consumo de eletrodomésticos como televisão (100\%), geladeira (100\%), no caso de aparelho de som/DVD, os indicadores de aquisição do bem ficaram entre $70 \%$ e $80 \%$; o uso de celulares ficou na ordem de $100 \%$ na EM, destacando-se sobre os demais. O indicador de uso da internet é ilustrativo da exclusão digital tão mencionada na literatura.

Torna-se importante destacar que nesta pesquisa não há pretensão de representatividade estatística, mas somente tomar essas porcentagens como indicadores para pensar na situação socioeconômica e na qualidade de vida dos participantes da pesquisa.

No Quadro 4 é apresentado um panorama do nível de escolaridade dos pais e/ou responsáveis de alunos e alunas que compuseram este estudo por escola. Cabe destacar que tomamos como referência a escolaridade da mãe, por ser esta a titular do Programa Bolsa Família em todos os casos deste estudo.

Quadro 4. Nível de escolaridade dos pais

\begin{tabular}{|c|c|c|c|c|c|c|c|c|c|c|c|c|}
\hline \multicolumn{13}{|c|}{ Níveis } \\
\hline \multirow{2}{*}{ Escolas } & \multicolumn{2}{|c|}{ Nenhuma } & \multicolumn{2}{|c|}{$\begin{array}{l}\text { Ens. fund. } \\
\text { incompleto }\end{array}$} & \multicolumn{2}{|c|}{$\begin{array}{l}\text { Ens. fund. } \\
\text { completo }\end{array}$} & \multicolumn{2}{|c|}{$\begin{array}{l}\text { Ens. médio } \\
\text { incompleto }\end{array}$} & \multicolumn{2}{|c|}{$\begin{array}{c}\text { Ens. médio } \\
\text { completo }\end{array}$} & \multicolumn{2}{|c|}{$\begin{array}{l}\text { Superior } \\
\text { completo }\end{array}$} \\
\hline & $n$ & $\%$ & $n$ & $\%$ & $n$ & $\%$ & $\mathrm{n}$ & $\%$ & $\mathrm{n}$ & $\%$ & $\mathrm{n}$ & $\%$ \\
\hline $\mathrm{CP}$ & - & - & 11 & $79 \%$ & - & - & 1 & $7 \%$ & 2 & $14 \%$ & - & - \\
\hline EM & - & - & 11 & $69 \%$ & 1 & $6 \%$ & 2 & $13 \%$ & 2 & $13 \%$ & - & - \\
\hline
\end{tabular}

Fonte: dados da pesquisa de campo 2010 e 2011 - Elaboração: GRANJA, Tania. 


\section{periferio}

É perceptível, no quadro acima, que o nível de escolarização dos pais concentra-se no ensino fundamental incompleto, do 4음 ano de escolaridade (antiga 3a série) até o 70 ano de escolaridade (antiga 6a série), quando muitos deles abandonaram a escola para trabalhar e/ou porque haviam repetido várias vezes. Contudo, a escolarização do responsável (pai) no grupo estudado é correspondente aos indicadores apurados relativos às mães, não havendo, portanto, nenhum diferencial significativo entre eles quanto ao total de anos de estudo.

O gráfico que segue amplia o panorama já mostrado, com a configuração da totalidade dos participantes, cujas informações referem-se a 30 dos 32 alunos e alunas.

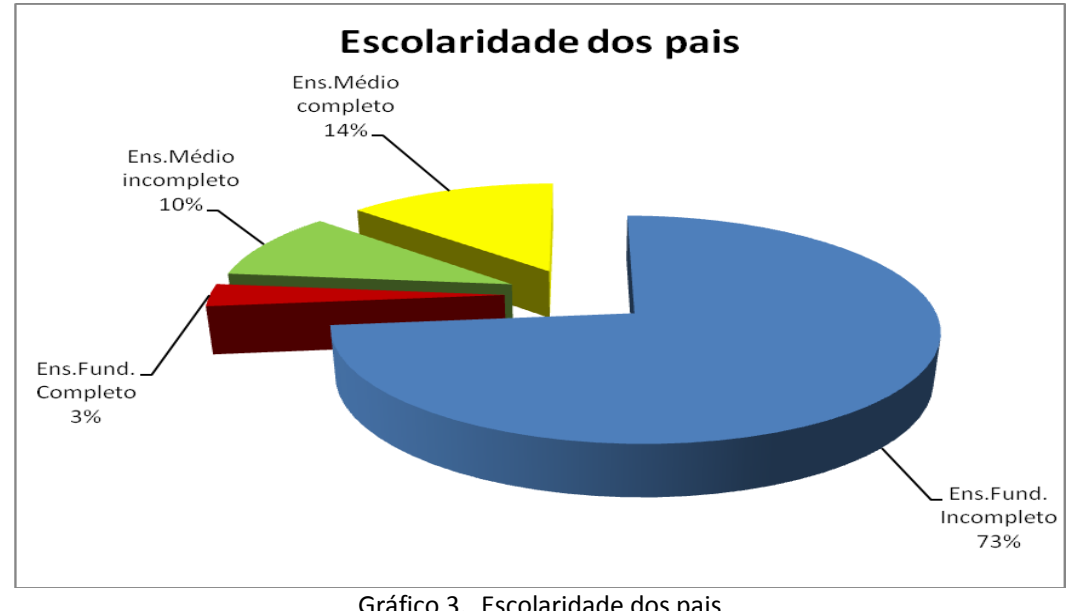

Fonte: dados da pesquisa de campo 2010 e 2011. Elaboração: Tânia Granja.

Os níveis de escolarização mostrados no Quadro 4 e os níveis de renda do Gráfico 1 guardam relação entre si: a exclusão escolar e, por conseguinte, a exclusão social.

\section{A ESCOLARIZAÇÃO}

É explicitado por Bourdieu (1999), em suas análises, que o capital cultural que cada família transmite direta ou indiretamente aos seus filhos é um fator que explica, de certo modo, as diferenças de êxito que se verificam em alunos e alunas ao longo do seu processo de escolarização. Assim, os participantes desta pesquisa, alunos e alunas 


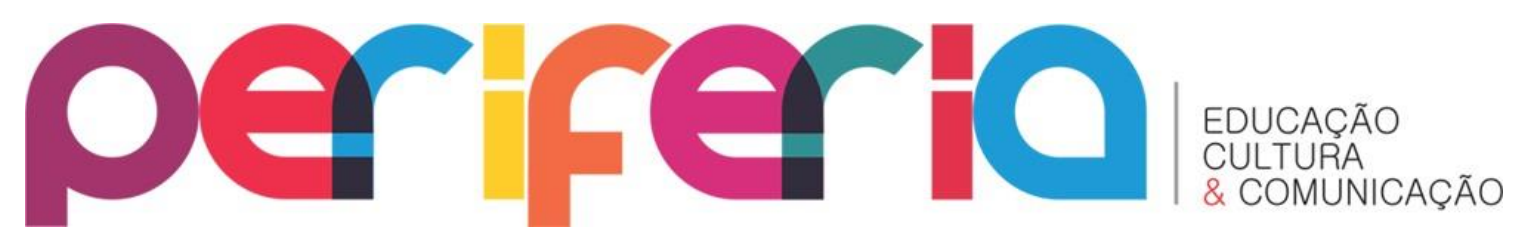

provindos de situação de desfavorecimento econômico e social, em que a ação do privilégio cultural não se encontra presente em suas vidas, acabavam por permanecer em desvantagem frente à experiência escolar e às exigências feitas pela instituição educacional. Bourdieu (1999) enfatiza a relação entre resultados escolares e origem social, em que o nível cultural dos pais tem influência no capital cultural acumulado pelas crianças e, consequentemente, sobre o êxito escolar, ainda que tenhamos variações.

Na nossa compreensão, o aluno que não traz consigo esse capital cultural acaba ficando mais vulnerável às intempéries da sofisticada "maquinaria escolar" (ALVAREZURÍA, 1996) durante seu processo de escolarização. Por outro lado, outra face da escola mostra que há hoje um enorme contingente de alunos e alunas provindos das camadas populares que vivem, segundo Freitas (2007), seu ocaso no interior das escolas, relegados a programas de recuperação, aceleração e de outras naturezas que adiam a eliminação da escola, dando outros contornos às desigualdades de oportunidades escolares.

\section{CONSIDERAÇÕES FINAIS}

Podemos inferir que os níveis de escolaridade dos pais e os níveis de renda guardam relação entre si: a exclusão escolar, constituindo extenso grupo social cuja baixa escolaridade acarretará certamente dificuldades para sua inserção e/ou permanência no mercado de trabalho. O que cada vez mais trará também dificuldades para acesso aos bens básicos e será limitante do aumento do seu padrão de vida.

$\mathrm{Na}$ perspectiva de que o conhecimento escolar pode ser socialmente distribuído com mais equidade, podemos pensar na distância que separa alunos e alunas provindos de grupos sociais mais pobres dos grupos privilegiados economicamente que, de acordo com o que tem sido estudado na literatura pertinente a essa questão, têm maiores e melhores oportunidades educacionais no interior do sistema de ensino. 


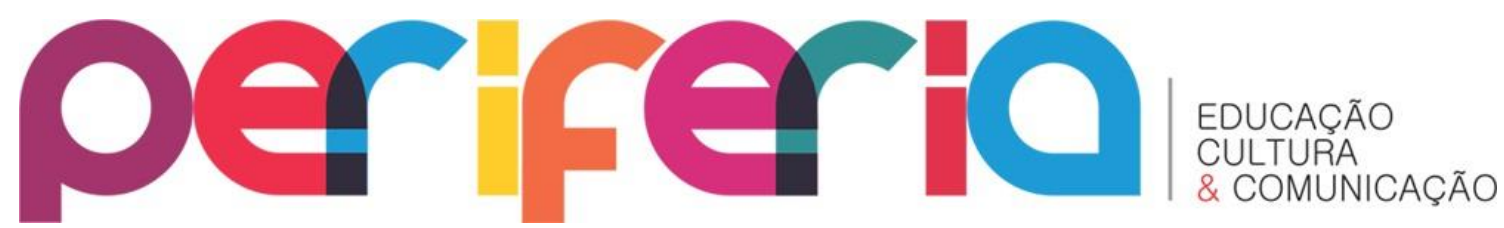

\section{REFERÊNCIAS}

ALVAREZ-URIA, Fernando. A escola e o espírito do capitalismo. In: COSTA, M. V.; GARCIA, R. L. Escola básica na virada do século. São Paulo: Cortez, 1996.

BOURDIEU, P. A escola conservadora: as desigualdades frente à escola e à cultura. In: NOGUEIRA, Maria Alice; CATANI, Afrânio (orgs.). Bourdieu: escritos de educação. Petrópolis: Vozes, 1999 (Ciências Sociais da Educação).

FREITAS, Luiz Carlos de. Eliminação adiada: o ocaso das classes populares no interior da escola e a ocultação da (má) qualidade do ensino. Educação \& Sociedade, Campinas, v. 28, no 100, out. 2007.

MONTALI, Lilia; TAVARES, Marcelo. Família, pobreza e acesso a programas de transferência de renda nas regiões metropolitanas brasileiras. Revista Brasileira de Estudos de População - Abep, São Paulo, v. 25, no 2, p. 211-231, jul/dez, 2008.

TRIBUNAL DE CONTAS DO ESTADO DO RIO DE JANEIRO - TCERJ - Secretaria Geral de Planejamento, Estudo Socioeconômico, Caxias, 2004. Disponível em:

<http://www.nima.pucrio.br/sobre nima/projetos/caxias/material de apoio/TCERJ/E studo Socioeconomico 2004 duquedecaxias.pdf> Acesso em 10 ago. 2012

TRIBUNAL DE CONTAS DO ESTADO DO RIO DE JANEIRO - TCERJ - Secretaria Geral de Planejamento, Estudo Socioeconômico, Caxias, 2006. Disponível em:

<http://www.nima.pucrio.br/sobre nima/projetos/caxias/material de apoio/TCERJ/E studo Socioeconomico 2006 duque de caxias.pdf> Acesso em 10 ago. 2012

TURA, Maria de Lourdes Rangel. A observação do cotidiano escolar. In: ZAGO, N.; CARVALHO, Marília P. de; VILELA, Rita Amélia T. (orgs). Itinerários de pesquisa: perspectivas qualitativas em Sociologia da Educação. 2ª ed. Rio de Janeiro: Lamparina, 2011. p. 183-206. 